\title{
Switched Capacitor Biquad Filter Using CDTA
}

\author{
Meeti Dehran ${ }^{1}$, Indu Prabha Singh ${ }^{1}$, Kalyan Singh ${ }^{2}$, Rabindra Kumar Singh ${ }^{3}$ \\ ${ }^{1}$ Department of Electronics and Communications Engineering, Shri Ramswaroop Memorial Group of \\ Professional Colleges (SRMGPC), Lucknow, India \\ ${ }^{2}$ Department of Physics and Electronics, R.M.L. University, Faizabad, India \\ ${ }^{3}$ Department of Electrical and Electronic Engineering, Kamla Nehru Institute of Technology (KNIT), Sultanpur, India \\ Email: meeti2012@gmail.com, induprabhasingh@gmail.com
}

Received July 20, 2013; revised August 20, 2013; accepted August 27, 2013

Copyright (C) 2013 Meeti Dehran et al. This is an open access article distributed under the Creative Commons Attribution License, which permits unrestricted use, distribution, and reproduction in any medium, provided the original work is properly cited.

\begin{abstract}
A switched capacitor biquad filter using current differencing transconductance amplifier (CDTA) is presented in this paper. The proposed circuit employs only one CDTA, two virtually grounded capacitors and one switched capacitor. It is a resistorless circuit, so it is beneficial to IC implementation in terms of space consideration. The proposed circuit is a second order single input multiple output (SIMO) current-mode filter. This filter can simultaneously realize all basic filter functions high pass, low pass and band pass responses without any component-matching conditions. All the active and passive sensitivities are low. The natural angular frequency $\left(\omega_{0}\right)$ and quality factor $(Q)$ of proposed filter can be electronically controlled. Owing to current mode operation it consumes less power. PSPICE simulation results are used to verify the theoretical analysis.
\end{abstract}

Keywords: Current Differencing Transconductance Amplifier (CDTA); Biquad Filter; Current-Mode Circuit

\section{Introduction}

Since the introduction of the current differencing transconductance amplifier (CDTA) in 2003, it has been acknowledged to be a versatile current-mode active building block in designing analog circuits [1]. This device with two current inputs and two kinds of current output provides an easy implementation of current-mode active filters [2]. It also exhibits the ability of electronic tuning by the help of its transconductance gain $\left(g_{m}\right)$. All these advantages together with its current-mode operation nature make the CDTA a promising choice for realizing the current-mode filters. As a result, a variety of CDTA applications has also been considered by various researchers.

The work in [2] introduces universal biquad filters which can simultaneously realize lowpass (LP), highpass (HP) and bandpass (BP) current responses. However, they suffer from the use of a large number of passive components. On the other hand, a lowpass filter circuit using CDTAs is proposed in [3]. However, this configuration is restricted for only lowpass transfer function design and it also requires an additional passive resistor. In [4], the CDTA-based current-mode single-input threeoutput filter is reported. It permits the realization of only three basic filter functions LP, BP, and HP responses simultaneously at high impedance output. While the circuit proposed in [5] requires four CDTAs, and an external passive resistor for its realization. In [6], a universal current-mode biquad, providing four basic transfer functions (low-pass, band-pass, high-pass, and band-reject) simultaneously is described. However, this circuit labors with the following drawbacks: 1) only the output current of the low-pass section flows to an independent load. All the remaining output currents flow through the working impedances and thus they cannot be directly utilized without negative influence on the filter behavior. 2) The additional resistor $R_{3}$ does not represent any increase of the filter versatility and thus it can be removed from the filter structure without decreasing its functionality. The paper published in [7] employed two CDTA to perform all three basic filter functions. Second order filter using single CDTA is published in $[8,9]$. The paper proposed in [8] provides only BP and HP outputs or LP and BP responses after interchanging RC network to $\mathrm{CR}$. The filter introduced in [9] uses single CDTA and provides several transfer functions depending on the position of applied input current, but at low frequency.

In this paper, a current-mode filter, consisting of a single CDTA, two grounded capacitors and one switched capacitor is used to realize the filter. It provides the ad- 
vantage of using switched capacitor instead of a resistor that is beneficial to IC implementation in terms of space consideration. The proposed circuit can be used as high pass, low pass, and band pass filter. PSPICE simulation results are used to verify the performance of the proposed circuit.

\section{CDTA}

Digital signal processing is becoming increasingly more powerful while advances in IC technology provide compact efficient implementation of its algorithms on silicon chips. Although many types of signal processing have indeed moved to digital domain, analog circuits are fundamentally necessary in many of today's complex, high performance systems. This is caused by the reality that naturally occurring signals are analog. Therefore analog circuits act as a bridge between the real world and digital systems. In the beginning, operational amplifiers were the main building blocks for analog circuit design. Unfortunately, their limited performance such as bandwidth, slew-rate etc. led the analog designer to search for other possibilities and other building blocks. As a result, new current-mode active building blocks such as Operational Transconductance Amplifiers (OTA), second generation Current Conveyors (CCII), Current-Feedback Op-Amps (CFOA), Differential Voltage Current Conveyor (DVCC), Differential Difference Current Conveyor (DDCC), third-generation Current Conveyor (CCIII), Dual X Current Conveyors (DXCCII), Current Controlled Current Conveyors (CCCII), Current Differencing Buffered Amplifier (CDBA) And Current Differencing Transconductance Amplifier (CDTA) receive considerable attention due to their larger dynamic range and wider bandwidth. Employing these new active elements for analog design and using CMOS technology for implementation, the circuit designers obtained new possibilities to solve their problems. CDTA device is a synthesis of the well-known advantages of the CDBA and an output transconductance amplifier to facilitate the implementation of currentmode analog signal processing.

The electrical symbol of the CDTA is shown in Figure 1.

The terminal relation of the CDTA can be characterized by the following set of Equation (1).

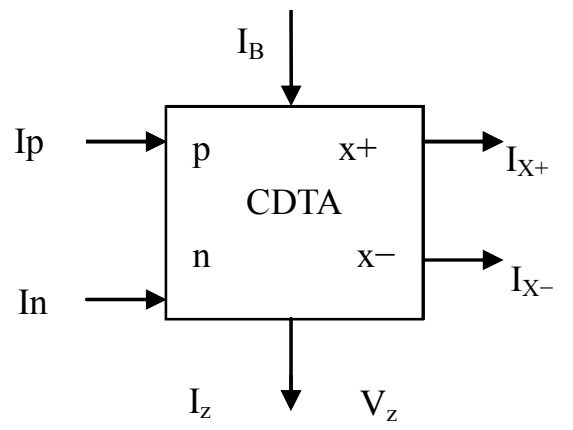

Figure 1. Electrical symbol of CDTA.

$$
\begin{gathered}
{\left[\begin{array}{c}
V_{p} \\
V_{n} \\
I_{z} \\
I_{x}
\end{array}\right]=\left[\begin{array}{cccc}
0 & 0 & 0 & 0 \\
0 & 0 & 0 & 0 \\
1 & -1 & 0 & 0 \\
0 & 0 & \pm g_{m} & 0
\end{array}\right]\left[\begin{array}{c}
I_{p} \\
I_{n} \\
V_{z} \\
0
\end{array}\right]} \\
V_{p}=V_{n}=0 \\
I_{z}=I_{p}-I_{n} \\
I_{x+}=g_{m} V_{z} \\
I_{x-}=-g_{m} V_{z}
\end{gathered}
$$

Where

$P$ and $n$ are input terminals;

$z$ and $\pm x$ are output terminals;

$g_{m}$ is the transconductance gain;

And $Z_{z}$ is external impedance connected at the terminal $z$.

According to above equation, the current flowing out of the terminal $z\left(I_{z}\right)$ is a difference between the currents through the terminals $p$ and $n\left(I_{p}-I_{n}\right)$. The voltage drop at the terminal $z$ is transferred to a current at the terminal $x\left(I_{x}\right)$ by a transconductance gain $\left(g_{m}\right)$, which is electronically controllable by an external bias current $\left(I_{B}\right)$. These currents, which are copied to a general number of output current terminals $x$, are equal in magnitude but flow in opposite directions.

The (CDTA) is composed of a unity-gain current source controlled by the difference of two input currents and a multi-output transconductance amplifier providing electronic tuning ability through its transconductance gain $\left(g_{m}\right)$. Therefore, this device is quite suitable for the synthesis of current-mode filters with electronically tunability properties. Moreover, the use of the CDTA as an active element provides the circuit implementations with a reduced number of passive elements, thereby leading to compact structures in some applications. All these advantages together with its current-mode operation nature make the CDTA a promising choice for implementing the current-mode continuous-time signal processing circuits consecutively.

Figure 2 shows a CMOS realization of the CDTA element [10]. The transistors M1 to M17 form the input DCCCS stage and M21 to M28 form the dual-output transconductor stage Aspect ratios of the transistors in Figure 2 are given in Table $\mathbf{1}$.

\section{Proposed Circuit}

The proposed current-mode multifunction filter employing CDTA, two grounded capacitors and a switched capacitor is shown in Figure 3.

Since all the grounded capacitors are employed, the circuit is suitable for IC implementation [11,12]. The switched capacitor (SC) functions as a resistor and re- 


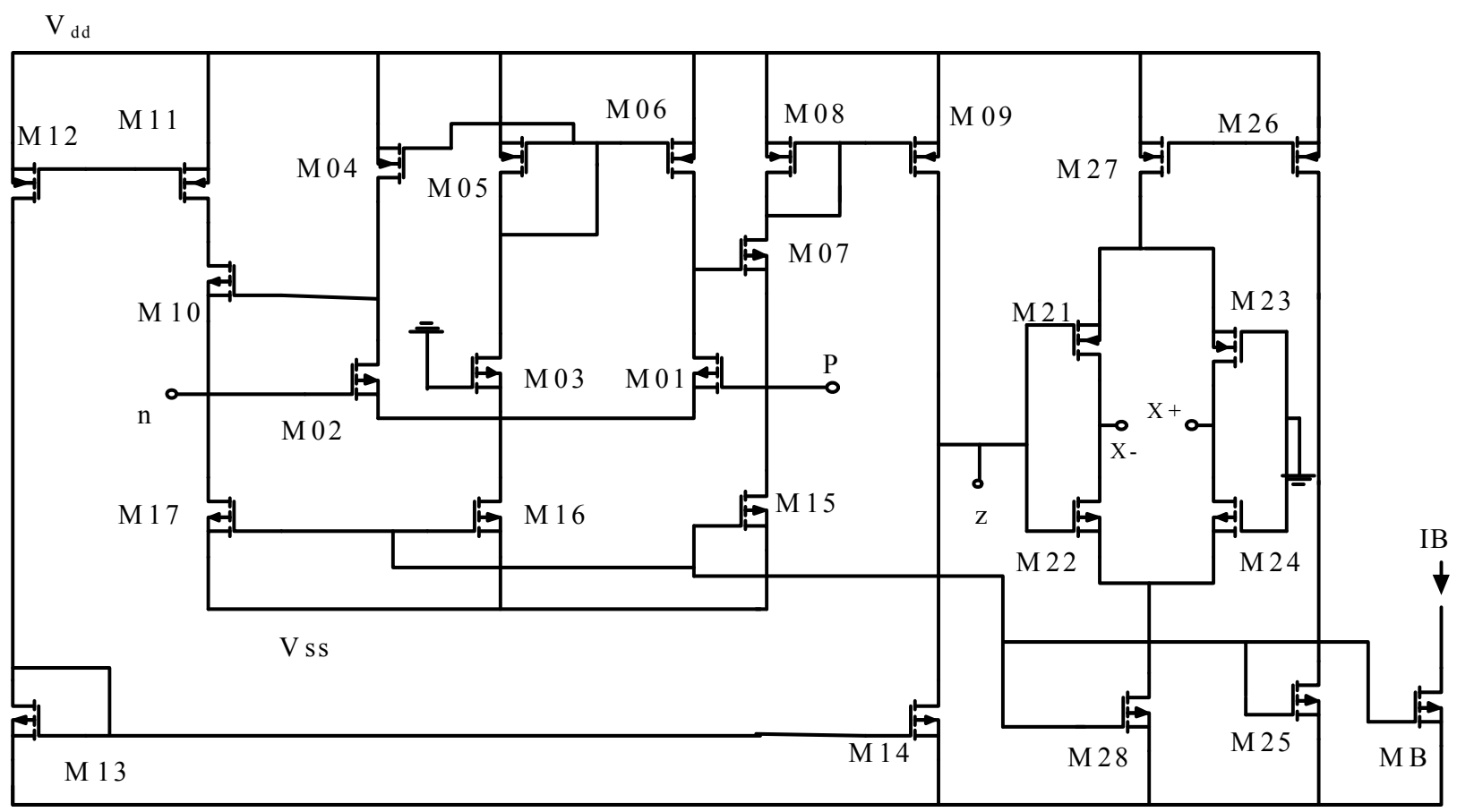

V ss

Figure 2. CDTA CMOS implementation from [10].

Table 1. Aspect ratios of the transistors.

\begin{aligned} & $\mathrm{M} 1=70 \mu \mathrm{m} / 0.7 \mu \mathrm{m}$ M15 $=35 \mu \mathrm{m} / 0.7 \mu \mathrm{m} \\ &$ M2 $=70 \mu \mathrm{m} / 0.7 \mu \mathrm{m}$ M16 $=35 \mu \mathrm{m} / 0.7 \mu \mathrm{m} \\ &$ M3 $=70 \mu \mathrm{m} / 0.7 \mu \mathrm{m}$ M17 $=35 \mu \mathrm{m} / 0.7 \mu \mathrm{m} \\ &$ M4 $=28 \mu \mathrm{m} / 0.7 \mu \mathrm{m}$ M21 $=28 \mu \mathrm{m} / 0.7 \mu \mathrm{m} \\ &$ M5 $=28 \mu \mathrm{m} / 0.7 \mu \mathrm{m}$ M22 $=16 \mu \mathrm{m} / 0.7 \mu \mathrm{m} \\ &$ M6 $=28 \mu \mathrm{m} / 0.7 \mu \mathrm{m}$ M23 $=28 \mu \mathrm{m} / 0.7 \mu \mathrm{m} \\ &$ M7 $=42 \mu \mathrm{m} / 0.7 \mu \mathrm{m}$ M24 $=16 \mu \mathrm{m} / 0.7 \mu \mathrm{m} \\ &$ M8 $=10.5 \mu \mathrm{m} / 0.7 \mu \mathrm{m}$ M25 $=56 \mu \mathrm{m} / 0.7 \mu \mathrm{m} \\ &$ M9 $=10.5 \mu \mathrm{m} / 0.7 \mu \mathrm{m}$ M26 $=59 \mu \mathrm{m} / 0.7 \mu \mathrm{m} \\ &$ M10 $=42 \mu \mathrm{m} / 0.7 \mu \mathrm{m}$ M27 $=56 \mu \mathrm{m} / 0.7 \mu \mathrm{m} \\ &$ M11 $=10.5 \mu \mathrm{m} / 0.7 \mu \mathrm{m}$ M28 $=56 \mu \mathrm{m} / 0.7 \mu \mathrm{m} \\ &$ M12 $=98 \mu \mathrm{m} / 0.7 \mu \mathrm{m}$ MB $=7 \mu \mathrm{m} / 0.7 \mu \mathrm{m} \\ &$ M13 $=10.5 \mu \mathrm{m} / 0.7 \mu \mathrm{m}$ M30 $=50 \mu \mathrm{m} / 0.7 \mu \mathrm{m} \\ &$ M14 $=10.5 \mu \mathrm{m} / 0.7 \mu \mathrm{m}$ M31 $=50 \mu \mathrm{m} / 0.7 \mu \mathrm{m} \\ &$\hline\end{aligned}

duces the required space for the fabrication. The $\mathrm{SC}$ is compatible with CMOS technology. The proposed circuit is able to perform the basic filter functions i.e. low pass, high pass, band pass. The low pass, high pass and band pass current outputs have been shown in Figure 3. From routine calculations for the proposed filter, the current responses can be given by:

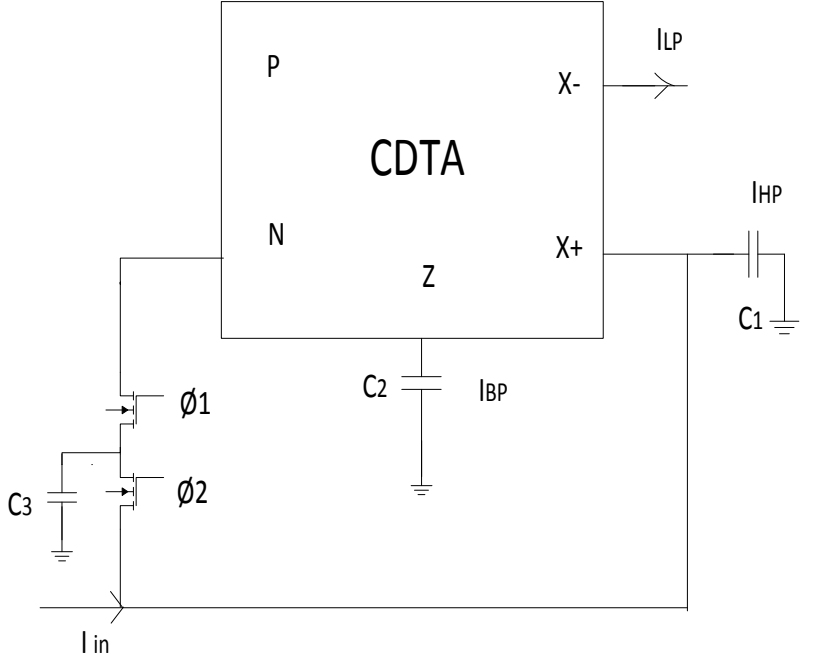

Figure 3. Biquad filter using CDTA element.

$$
\begin{gathered}
I_{L P}=\frac{\frac{g_{m}}{R C_{1} C_{2}}}{S^{2}+\frac{1}{R C_{1}} S+\frac{g_{m}}{R C_{1} C_{2}}} I_{i n} \\
I_{B P}=-\frac{\frac{1}{R C_{1}} S}{S^{2}+\frac{1}{R C_{1}} S+\frac{g_{m}}{R C_{1} C_{2}}} I_{\text {in }}
\end{gathered}
$$




$$
I_{H P}=\frac{S^{2}}{S^{2}+\frac{1}{R C_{1}} S+\frac{g_{m}}{R C_{1} C_{2}}} I_{i n}
$$

Bandwidth $(B W)$, natural frequency $\left(\omega_{0}\right)$ and quality factor $(Q)$ are given by

$$
B W=\frac{1}{R C_{1}}, \omega_{0}=\sqrt{\frac{g_{m}}{C_{1} C_{2} R}}, Q=\sqrt{g_{m} R \frac{C_{1}}{C_{2}}}
$$

From Equation (5), the parameter $\omega_{0}$ can be controlled by transconductance $g_{m}$ independently of bandwidth. The transconductance values can be changed through adjusting the biasing current of the CDTA.

From the expression of Equation (5), the sensitivities of $\omega_{0}$ and $Q$ to variations in various parameters is given as

$$
\begin{aligned}
& S_{g_{m}}^{\omega_{0}}=\frac{1}{2}, S_{C_{1}, C_{2}, R}^{\omega_{0}}=-\frac{1}{2}, S_{g_{m}}^{Q}=\frac{1}{2}, \\
& S_{C_{1}, R}^{Q}=\frac{1}{2}, S_{C_{2}}^{Q}=-\frac{1}{2}
\end{aligned}
$$

Hence all the sensitivities are low as calculated in Equation (6).

The value of the capacitor $C_{3}$ used in switched capacitor is calculated using the formula given as

$$
C_{3}=\frac{1}{R f}
$$

Where, $R$ is the equivalent resistance value of the switched capacitor and $f$ is the frequency of clock signal $\left(\Phi_{1}\right)$ and $\left(\Phi_{2}\right)$, applied at two mosfets (M30, M31) of switched capacitor.

\section{Simulation Results}

The performance of the proposed filter is verified using the simulation in PSpice. According to the analysis from Sections 2 and 3, the single input excitation is given. The CDTA model employing the n-well CMOS process TSMC $0.35 \mathrm{~mm}$ is used. The transconductanceis set to $888 \mu \mathrm{S}$ via a bias current of $40 \mu \mathrm{A}$.

As an example design, the capacitors $C 1=C 2=10 \mathrm{pF}$, $C_{3}=2.96 \mathrm{pF}$ and the biasing current $I_{\text {bias }}=40 \mu \mathrm{A}$ are given. This setting has been designed to obtain the LP, $\mathrm{BP}$ and HP, filter responses. The simulated responses of the BP, LP and HP of the proposed filter are shown in Figure 4. Both the natural frequency and the quality factor are in accordance with the proposed values.

\section{Conclusion}

A 2nd-order single input multiple output (SIMO) current-mode filter employing a single CDTA is described in the paper. The natural angular frequency $\omega_{0}$ and the bandwidth $\omega_{0} / Q$ can electronically be controlled by ad-

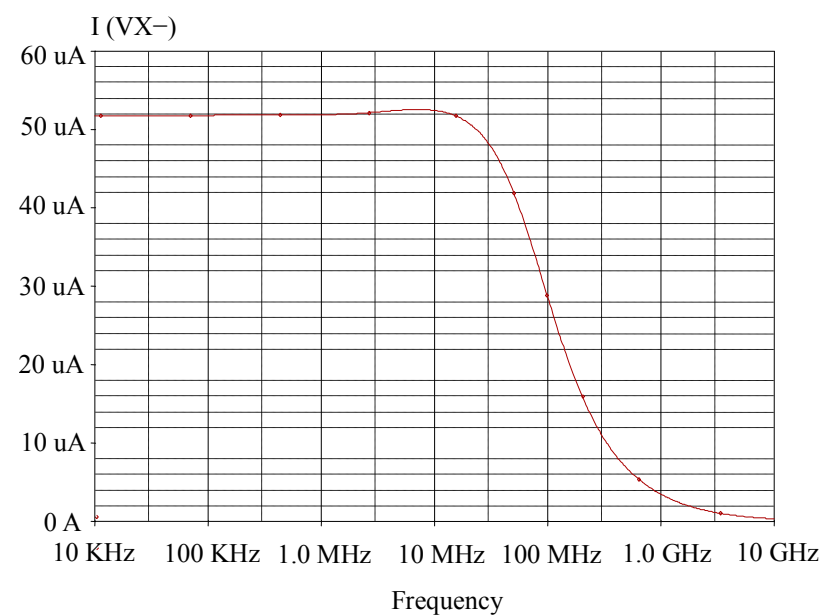

(a)

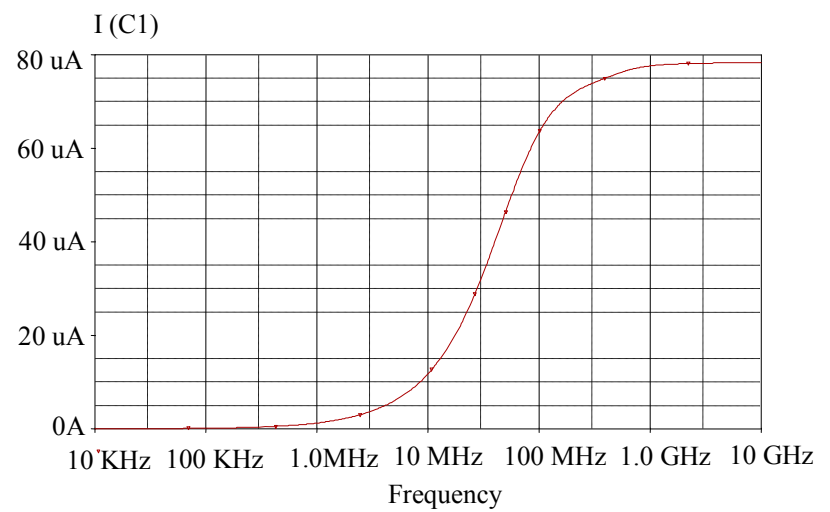

(b)

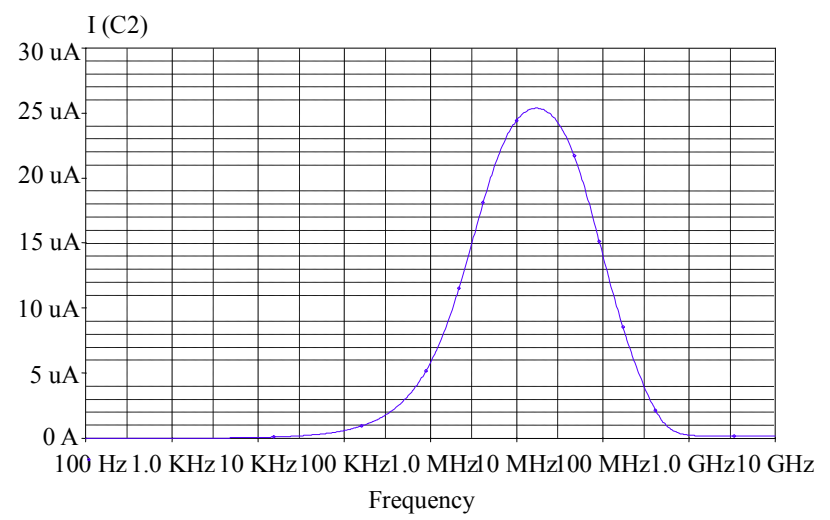

(c)

Figure 4. Response of biquad filter using CDTA element. (a) Low pass response; (b) High pass response; (c) Band pass response.

justing the transconductance gain $g_{m}$ of the CDTA. The simulated responses with PSPICE have been used to prove the theory. It possesses the properties as the following: 1) employment of only grounded capacitors which is suitable for IC implementation; 2) ability of realizing the LP, $\mathrm{BP}$, and HP filter responses without any componentmatching condition; and 3) Electronic control of the pa- 
rameter $\omega_{0}$. The switched capacitor has good linearity. The PSPICE simulation results demonstrate the close agreement with the presented theory.

\section{REFERENCES}

[1] D. Biolek, "CDTA-Building Block for Current-Mode Analog Signal Processing," Proceedings of European Conference on Circuit Theory and Design (ECCTD), Poland, 1-4 September 2003, pp. 397-400.

[2] D. Biolek and V. Biolkova, "Universal Biquad Using CDTA Elements for Cascade Filter Design," Proceeding of 7th International Multiconference on Circuits, Systems Communications and Computers (CSCC), Athens, 7-9 July 2003, pp. 8-12.

[3] A. T. Bekri and F. Anday, "Nth-Order Low-Pass Filter Employing Current Differencing Transconductance Amplifiers," Proceeding of the 2005 European Conference on Circuit Theory and Design, Cork, 28 August-2 September 2005, pp. 193-196.

http://dx.doi.org/10.1109/ECCTD.2005.1523026

[4] D. Biolek and V. Biolkova, "CDTA-C Current-Mode Universal 2nd Order Filter," Proceeding of the 5th WSEAS International Conference on Applied Informatics and Communications, Malta, 15-17 September 2005, pp. 411-414.

[5] W. Tanjaroen, T. Dumawipata, S. Unhavanich, W. Tangsrirat and W. Surakampontorn, "Design of Current Differencing Transconductance Amplifier and Its Application to Current-Mode KHN Iquad Filter," Proceeding of ECTICON, Ubon Ratchathani, 10-13 May 2006, pp. 497-500.

[6] D. Prasad, D. R. Bhaskar and A. K. Singh, "Universal Current-Mode Biquad Filter Using Dual Output Current
Differencing Transconductance Amplifier," International Journal of Electronics and Communications, Vol. 63, No. 6, 2008, pp. 497-501.

[7] A. Uygur and H. Kuntman, "Design of a Current Differencing Transconductance Amplifier (CDTA) and Its Application on Active Filters," SIU'2005: IEEE 13th Signal Processing and Communication Applications Conference, Kayseri, 16-18 May 2005, pp. 340-343.

[8] N. A. Shah, M. Quadri and S. Z. Iqbal, "Current Mode Multifunction Filter Using Current Differencing Transconductance Amplifier," Indian Journal of Pure \& Applied Physics, Vol. 45, No. 9, 2007, pp. 767-769.

[9] D. Biolek, V. Biolkova and Z. Kolka, "Single-CDTA (Current Differencing Transconductance Amplifier) CurrentMode Biquad Revisited," WSEAS Transactions on Electronics, Vol. 5, No. 6, 2008, pp. 250-257.

[10] D. Biolek, E. Hancioglu and A. U. Keskin, "High-PerforMance Current Differencing Transconductance Amplifier and Its Application in Precision Current-Mode Rectification," International Journal of Electronics and Communications, Vol. 62, No. 2, 2008, pp. 92-96. http://dx.doi.org/10.1016/j.aeue.2007.03.003

[11] M. Bhusan and R. W. Newcomb, "Grounding of CapaciTors in Integrated Circuits," Electronics Letters, Vol. 3, No. 4, 1967, pp. 148-149. http://dx.doi.org/10.1049/el:19670114

[12] K. Pal and R. Singh, "Inductor Less Current Conveyor All Pass Filter Using Grounded Capacitors," Electronics Letters, Vol. 18, No. 1, 1982, p. 47. http://dx.doi.org/10.1049/el:19820033 